Egyptian Journal of Aquatic Biology \& Fisheries

Zoology Department, Faculty of Science,

Ain Shams University, Cairo, Egypt.

ISSN $1110-6131$

Vol. 23(5): 313 - 325 (2019)

www.ejabf.journals.ekb.eg

\title{
Ultrastructural study of the ovary and oogenesis of Polyonchobothrium clarias Woodland, 1925 (Cestoda: Bothriocephalidea) infecting Clarias gariepinus from Egypt.
}

\author{
Sabry E. El-Sayed ${ }^{1}$, Azza A. Taeleb ${ }^{1}$, Salwa Z. Arafa ${ }^{1}$, Sameh S. Ali ${ }^{1}$ \\ and Hewaydah E. Abou Shafeey ${ }^{2 *}$ \\ 1- Department of Zoology, Faculty of Science, Zagazig University, Egypt \\ 2- Department of Zoology, Faculty of Science, Tanta University, Egypt \\ *Corresponding Author: hewaydah@yahoo.com
}

\begin{tabular}{l} 
ARTICLE INF \\
Article History: \\
Received: Dec. 9, 201 \\
Accepted:Dec. 22, \\
Online: Dec. 25, 2019 \\
\hline Keywords: \\
P. clarias \\
Bothriocephalidae \\
Clarias gariepinus \\
Oogenesis \\
Ovarian tissues \\
Ultrastructure
\end{tabular}

\section{ARTICLE INFO}

Ultrastructure

\begin{abstract}
The ovarian tissues and different stages of oocytes development of Polyonchobothrium clarias Woodland, 1925 recovered from the intestine of Clarias gariepinus Burchell, 1822 fish was investigated by transmission electron microscope (TEM). The ovarian follicles are enveloped by compressed epithelial sheath lying on basal layer that shows epithelial projection into the lumen of each follicle. The epithelial sheath filled with glycogen, mitochondria and solitary lipid droplets. The epithelial nuclei are appeared closed to the basal part of the ovarian follicle. Numerous heterogeneous electron dense myelin-like bodies observed within the ovarian cytoplasm they appeared different irregular shaped. Each ovarian follicle contains number of oocytes loosely packed within the follicle at different stages of differentiation developmental stages starting with oogonial cells, primary, secondary and mature oocytes. The Oogonia were undergoing characteristic cytological changes that lead to oocyte maturation. Vitelline material appears in early stages of primary oocytes. Lipid droplets appeared in late stages of secondary oocyte. Mature oocytes are filled with clusters of cortical granules adjacent to the oocyte plasma membrane. Syncytial interstitial tissue and number of myelin-like bodies are observed in the ovarian cytoplasm and they fill the cytoplasmic spaces. The results of the present study were compared with the previous reports in other cestode taxa, to define the ultrastructural observations of the female reproductive tissues for clarification the reproductive fecundity of the parasite.
\end{abstract}

\section{INTRODUCTION}

The reproductive system of the eucestodes contains a single or numerous testes and a single lobed or un-lobed ovary with the connecting oviduct and uterus (Cheng, 1986 and McDougald, 2003). In most tapeworm species, the male organs mature first. The female reproductive system of Platyhelminthes show great morphological variability with significant differences in anatomical organisation and cell structure by taxonomy (Adiyodia and Adiyodi, 1988). The reproductive fecundity of cestodes is among the highest of any animal group, a single hermaphroditic individual of many species may produce millions of eggs in a life time; in addition, the eggs produced by tapeworms are very complex, consisting of a larva surrounded by various embryonic envelopes and other protective layers (Ubelaker, 1983). 
Studies have shown that the general pattern of oocyte development in parasitic Platyhelminthes revealed that the oogonial cells at the periphery of the ovary divide to form primary oocytes which enlarge to mature cells that fill the interior of the ovary. However it revealed that the main pattern of oogenesis is basically similar in digeneans (Bjorkman and Thorshell, 1964; Gresson, 1964; Holy and Wittrock, 1986; Orido, 1987; 1988 and Podvyaznaya, 2003), as well as in mongeneans (Halton et al., 1976 and Tappenden, et al., 1993) and in cestodes (Poddubnaya et al., 2005a; b; Poddubnaya et al., 2007 and Taeleb and Gobashy, 2014).

Light microscopical studies on tapeworm oogenesis and embryogenesis were accomplished by Douglas (1963) and Rybicka (1966) which revealed that the first meiotic division occurs after the oocytes leaves the ovary and is completed with entry of sperm into the oocyte. Ultrastructural studies of the oogenesis have been carried out revealed the details structures of the ovarian sheath and different stages of oocytes in several orders of cestodes; as in Gyrocotylidea (Poddubnaya et al., 2010), Caryophyllidea (Davydov et al., 1994; Poddubnaya, 2003b and Poddubnaya, et al. 2003), Proteocephalidea (Korneva and Davydov, 2001 and Korneva, 2001a), Pseudophyllidea (Korneva, 2002, Poddubnaya, 2002 and 2003a), Spathebothriidea (Poddubnaya et al., 2005a, b and Poddubnaya et al., 2007) and in Cyclophyllidea (Taeleb and Abdel-Moaty, 2011 and Taeleb and Gobashy, 2014). There are limited ultrastructural data available on the structure of the ovarian tissues and oocyte development of Bothriocephalidea order to which P. clarias belonged.

The process of oogenesis of $P$. clarias has not been previously detected. In Egypt, recent ultrastructural morphological data available on $P$. clarias on its body surface using SEM (Ibrahim et al., 2008 and Abdel-Gaber et al., 2016). The present study was conducted to provide detailed investigation of the ovarian tissue and different stages of the oocytes development of $P$. clarias using transmission electron microscope, and compare the results of the previous reports in other cestode taxa, to define the ultrastructural observations of the female reproductive tissues for clarification the reproductive fecundity of the parasite.

\section{MATERIALS AND METHODS}

Adult specimens of Polyonchobothrium clarias were collected alive from the intestine of naturally infected Clarias gariepinus caught from different Nile derivatives in Al-Qaliobiah province and in some fish farms in Sharqiyah province, Egypt. For transmission electron microscopy (TEM), specimens were rinsed in $0.9 \mathrm{Na}$ $\mathrm{Cl}$ solutions and immediately fixed with $2.5 \%$ glutaraldehyde in $0.1 \mathrm{M}$ phosphate buffer (PH 7.3) for $2 \mathrm{~h}$ at $4^{\circ} \mathrm{C}$, then washed in two changes of sodium cacodylate buffer ( $\mathrm{pH} 7.4$ ) for 15 minutes. Specimens were post-fixed in cold $1 \%$ osmium tetroxide (OsO4) for one hour and washed again in sodium-cacodylate buffer. Fixed worms were then dehydrated in ascending series of ethanol, passed in two changes of propylene oxide for 15 minutes each and embedded in epoxy resin (Epon 812). Specimens were placed in gelatine capsules with pure resin and polymerized at 60 $80^{\circ} \mathrm{C}$ for $24-48$ hours. The capsules were cut on LEICA EM UC6 ultra-microtome by glass knives into semi thin sections $(1.0 \mu$ thick) for light microscopy, and ultrathin sections $(50-200 \mathrm{~nm})$ for electron microscopy. Sections were carried on copper grids and stained by uranyl acetate followed by lead citrate. Ultrathin sections were examined in a Joel - JEM/ 1010 transmission electron microscope at $80 \mathrm{Kv}$. 


\section{RESULTS}

Transmission electron micrographs show that oogonial development begins by the formation of oogonia that undergo division to primary oocytes followed by the formation of-secondary oocytes which in turn undergo division to mature oocytes. The ovary of $P$. clarias is lobulated and located in the lateral portion of the mature proglottides. The lumen of the ovary is lined by a thin compressed ovarian epithelial layer that has narrow projections; ovary is composed of ovarian follicles aggregated to each other, each ovarian follicle is enveloped by compressed epithelial sheath lying on the basal layer of ovarian wall that shows epithelial projection into the lumen of follicle (Fig. 1a). The epithelial sheath filled with glycogen, mitochondria and solitary lipid droplets, where epithelial nuclei are closed to the basal part of the ovarian follicle (Figs.1b-e). The interstitial nuclei are usually located in the peripheral area of the follicle; they appeared round or oval with or without a nucleolus and they consists of significant patches of dispersed electron dense heterochromatin (Figs.1d, e). Numerous heterogeneous electron dense myelin-like bodies (specific types of bodies which are components of the interstitial cytoplasm of the ovary) are observed within the ovarian cytoplasm and have irregular shape (Fig.1e).
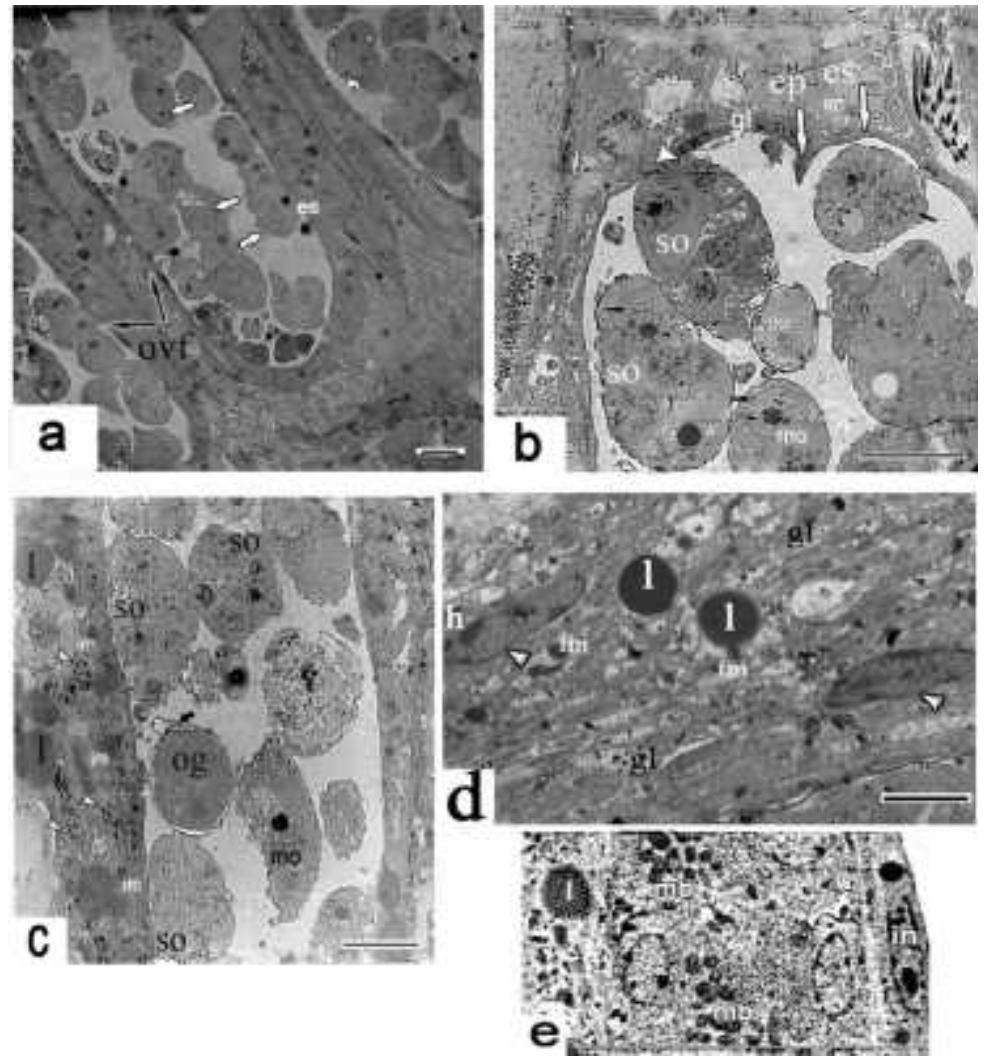

Fig. 1: Transmission electron micrographs of the ovarian tissue and oocytes (a-d) of Polyonchobothrium clarias showing.

a. Ovarian follicles (ovf), epithelial sheath (es), oocytes (arrows).

b. Oogonial cells (og), secondary oocytes (so), mature oocytes (mo), epithelial sheath (es), epithelial projection (ep), oocytes nucleus (arrow), oocytes nucleolus (arrow head), glycogen (gl), mitochondria (m), interstitial nucleus (n), interstitial mitochondria (im).

c. Interstitial nuclei (arrow heads), lipid droplet (1), Oogonial cells (og), secondary oocytes (so), mature oocytes (mo), Oogonial mitochondria (arrow) interstitial mitochondria (im).

d. enlarged part of interstitial syncytium showing; interstitial mitochondria (im), glycogen (gl), interstitial nucleus (n), lipid droplets (l), heterochromatin (h).

e. enlarged part of interstitial syncytium showing; myelin-like bodies (mb), interstitial nucleus (n), lipid droplet (l). Scale bar: $10 \mu \mathrm{m}$ (a-c, e), $2 \mu \mathrm{m}$ (d). 
Each ovarian follicle contains number of loosely packed oocytes at different stage of differentiation namely oogonial cells, primary, secondary and mature oocytes (Figs. 1b, c).

\section{Oogonia}

Oogonia are often semi oval in shape, having little cytoplasm and a large irregular nucleus that have a prominent nucleolus. The cytoplasm is filled with free ribosomes and contains a few mitochondria situated at periphery of these cells. The oogonial cells are located at periphery of the ovarian follicle (Figs. 1b, c).

\section{Primary oocytes}

Primary oocytes located near the follicular epithelium and they are larger than the oogonia. Each of them has a large nucleus and a well-defined nucleolus. Their nuclei contain opaque patches of chromatin (Fig. 2a). The cytoplasm is filled with free ribosomes and granular endoplasmic reticulum (GER). Few mitochondria arranged through the peripheral cytoplasm (Fig. 2a). Golgi complex and accumulation of vitelline materials that appeared as electron dense granules were observed in early maturing primary oocytes. During the growth of the oocytes, the number of mitochondria and the volume of the cytoplasm have increased (Figs. 2a-d). A single centriole can be observed within the cytoplasm near the nucleus of the mature primary oocytes (Fig. 2d). Figure 2e shows a nucleic division in those mature cells.
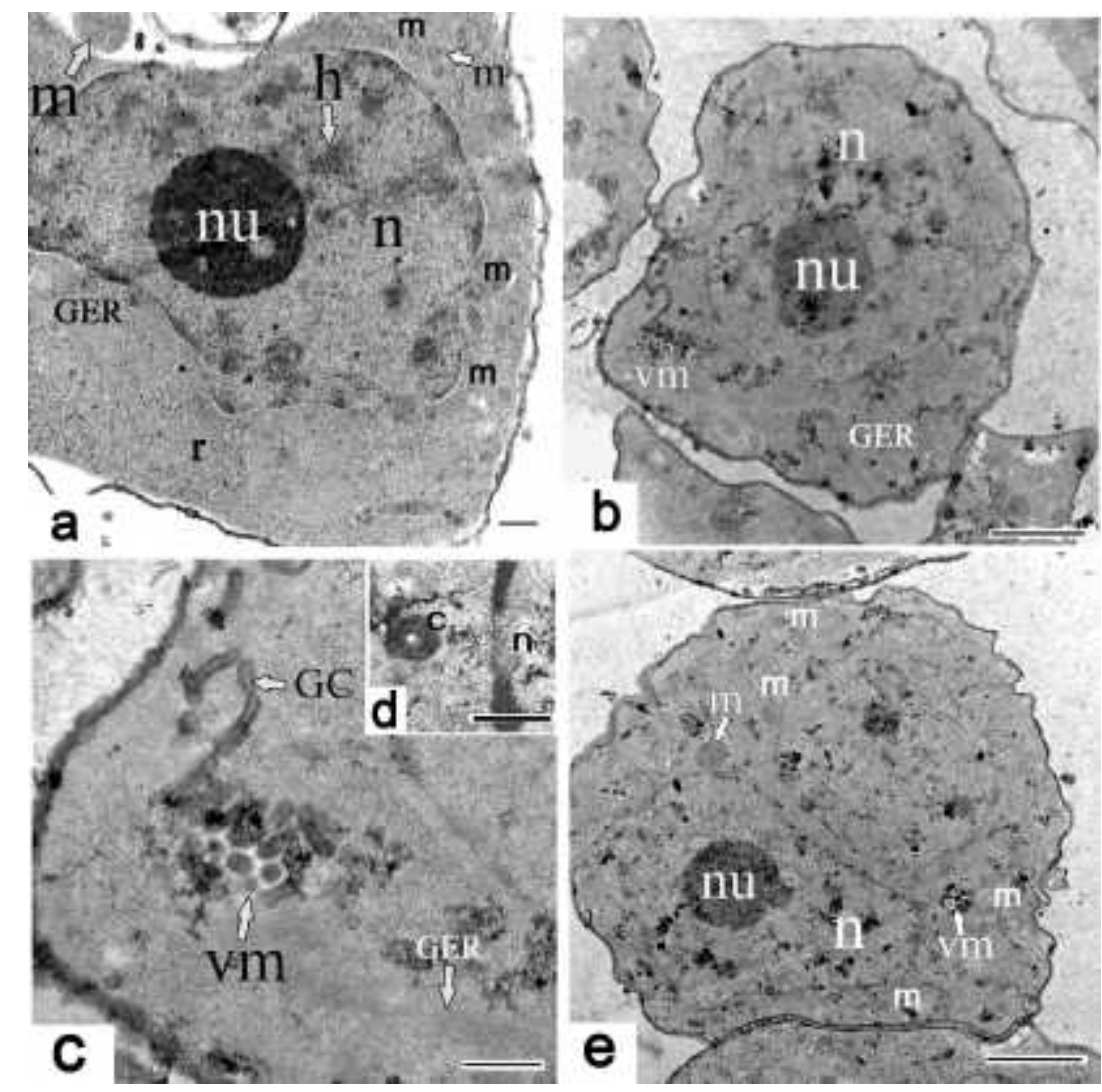

Fig. 2: Transmission electron micrographs of primary oocytes (a-e) of Polyonchobothrium clarias showing.

a. irregular large nucleus $(\mathrm{n})$, heterochromatin patches $(\mathrm{h})$, nucleolus $(\mathrm{nu})$, ribosomes $(\mathrm{r})$, mitochondrion $(\mathrm{m})$, granular endoplasmic reticulum (GER).

b. nucleus (n), nucleolus (nu), vitelline materials (vm), granular endoplasmic reticulum (GER).

c. Golgi complex (GC), vitelline materials (vm), nucleus (n), granular endoplasmic reticulum (GER).

d. enlarged part of primary oocyte showing a centriole (c), nucleus (n)

e. primary oocyte with divided nucleus $(\mathrm{n})$, nucleolus $(\mathrm{nu})$, mitochondrion $(\mathrm{m})$, vitelline materials (vm). Scale bar: $500 \mu \mathrm{m}(\mathrm{a}, \mathrm{c}, \mathrm{d}), 2 \mu \mathrm{m}(\mathrm{b}, \mathrm{e})$. 


\section{Secondary oocytes}

The cytoplasmic volume of secondary oocytes is larger than that of oogonia and primary oocytes. Each secondary oocyte has a small and spherical nucleus with small prominent nucleolus (Fig. 3a). Some of secondary oocytes have numerous nucleoli which are localized in the peripheral area of the cytoplasm (Figs. 3b, c). Golgi complex cisternae, mitochondria and GER have been observed situated throughout the cytoplasm (Fig. 3d).

Late secondary oocytes are distinguished by large number of mitochondria (Figs. 3b, d) and Golgi complexes which are in the form of short rods (Fig. 3d) or small vacuole-like structures (Figs. 4a-d) that lie just adjacent to the endoplasmic reticulum and mitochondria (Figs. 4c and 5a).

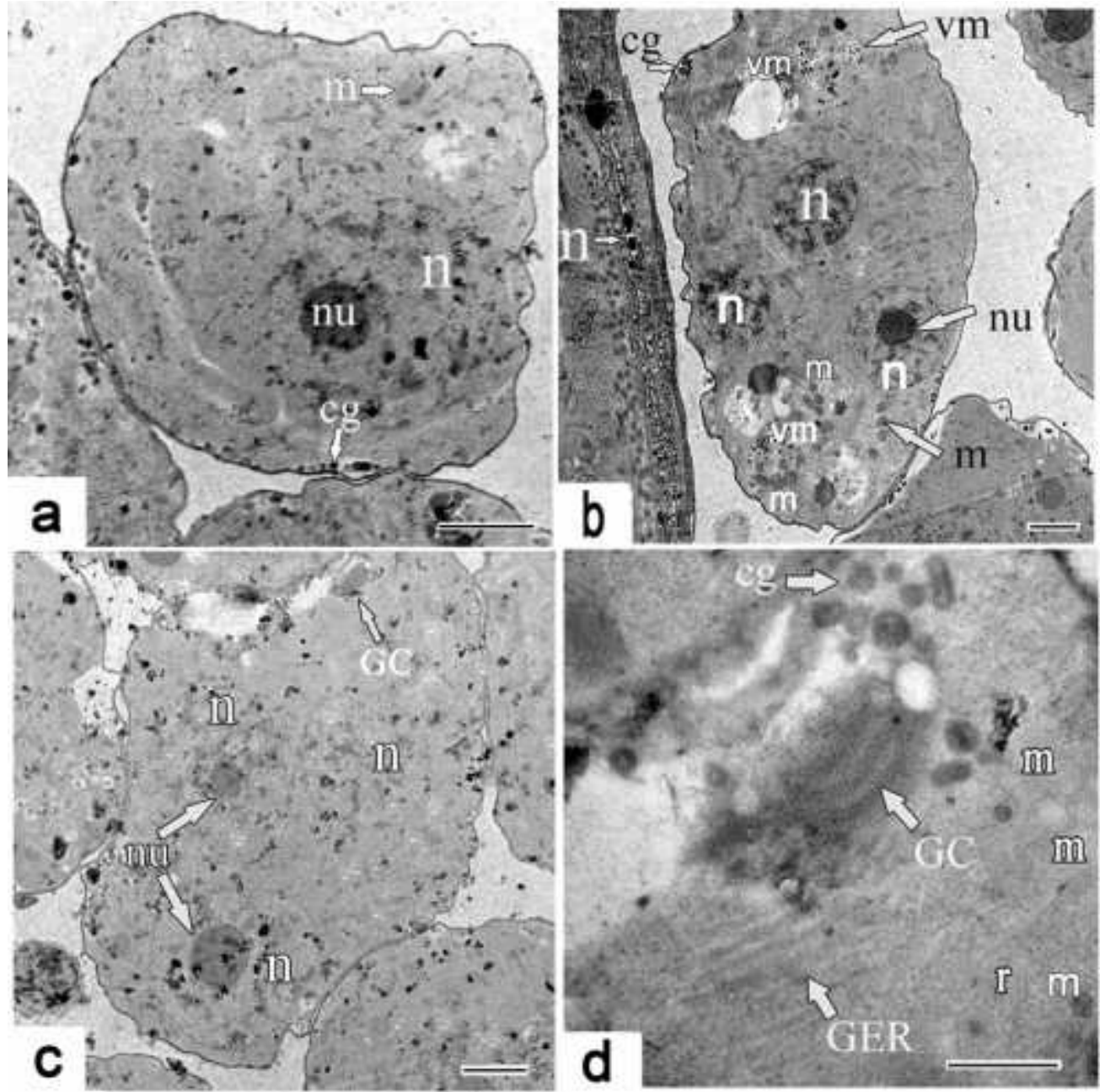

Fig. 3: Transmission electron micrographs of secondary oocytes (a-d) of Polyonchobothrium clarias showing.

a. cortical granules (cg), single nucleus (n), nucleolus (nu), mitochondria (m).

b. vitelline materials (vm), cortical granules (cg), three nuclei (n), nucleolus (nu), mitochondria (m).

c. Golgi complex (GC), three nuclei (n), nucleolus (nu).

d. enlarged part of $\mathrm{c}$ showing rod-shape Golgi complex (GC), ribosomes (r), granular endoplasmic reticulum (GER), mitochondria (m), cortical granules (cg).

Scale bar: $2 \mu \mathrm{m}(\mathrm{a}-\mathrm{c}), 500 \mu \mathrm{m}(\mathrm{d})$. 
Accumulation of ovoid, or spherical and membrane bounded heterogeneously electron dense granules (cortical granules) and few oval lipids droplets are located within the peripheral ooplasm adjacent to oocytes membrane (Figs 3d, 4a, c, 5b). Dense materials resemble early cortical granules form within the vesicular Golgi cisternae (Figs. 3b, 4b). The vesicles merge and their contents condense producing fully formed vitelline granules (Figs. 4c, d). Spherical and oval electron-dense lipid droplets occur singly (Fig. 4a) or in groups (Figs. 5b, c) are appeared within cytoplasm of oocytes. Ribosomes are observed free in the cytoplasm (Fig. 3d) or associated with the endoplasmic reticulum (Figs. 4d and 5c). However, the most notable feature of the late secondary oocytes is the appearance of homogeneous spherical electron-dense granules inside small vesicles arising from the Golgi complexes which are observed deeply within the ooplasm (Figs. 3b and 4b).

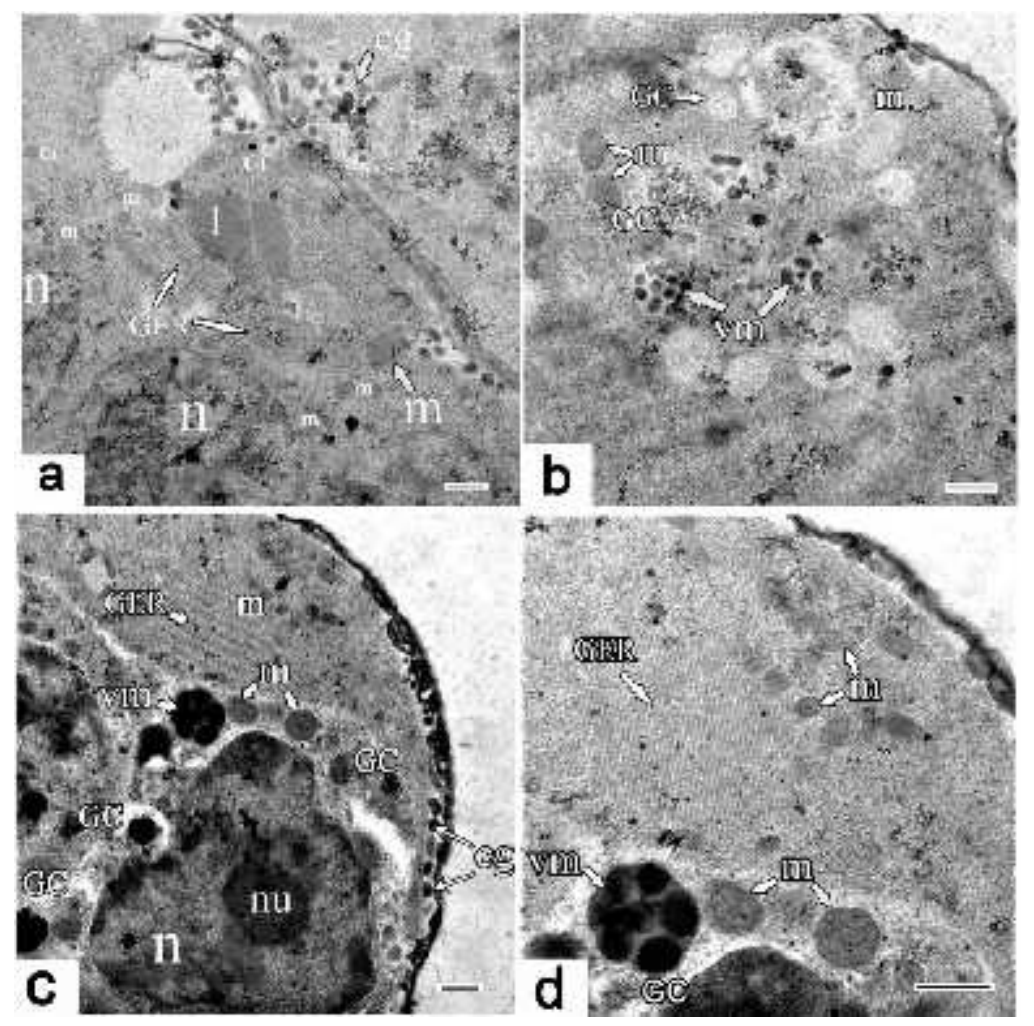

Fig. 4: Transmission electron micrographs of late secondary oocytes (a-d) of Polyonchobothrium clarias showing.

a. lipid droplet (l), granular endoplasmic reticulum (GER), mitochondria (m), cortical granules (cg), nucleus (n).

b. vitelline materials (vm), mitochondria (m), Golgi complex (GC).

c. cortical granules (cg), nucleus (n), nucleolus (nu), mitochondria (m). vitelline materials (vm), Golgi complex mass (GC) adjacent to granular endoplasmic reticulum (GER).

d. enlarged part of c showing vitelline materials in clusters (vm), Golgi complex (GC), granular endoplasmic reticulum (GER), mitochondria (m).

Scale bar: $2 \mu \mathrm{m}(\mathrm{a}-\mathrm{c}), 500 \mu \mathrm{m}(\mathrm{d})$. 


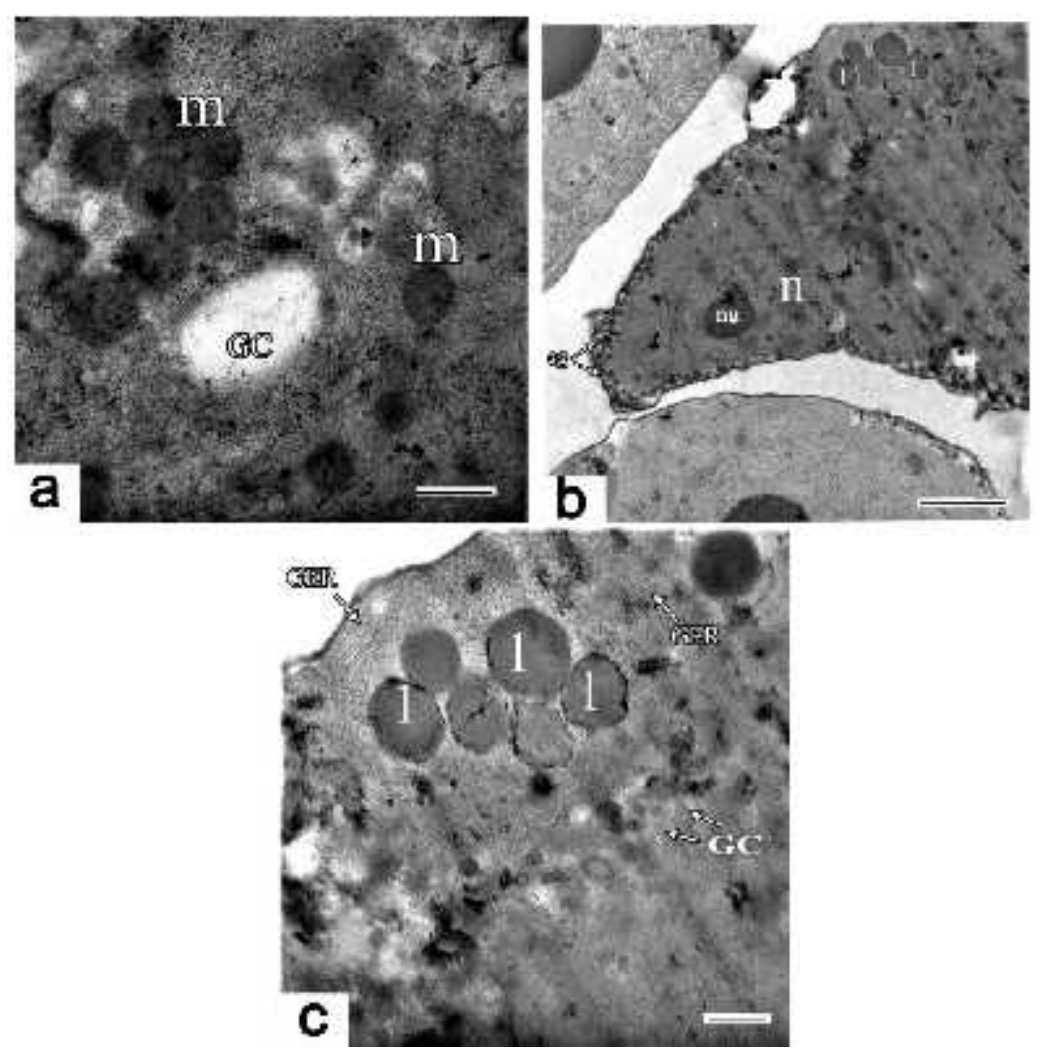

Fig. 5: Transmission electron micrographs of late secondary oocytes (a-c) of Polyonchobothrium clarias showing.

a. enlarged Golgi complex (GC) adjacent to numerous mitochondria (m).

b. small lipid droplets, nucleus (n), nucleolus (nu), cortical granules (cg).

c. numerous lipid droplets (1), ribosomes associated with granular endoplasmic reticulum (GER).

Scale bar: $500 \mu \mathrm{m}(\mathrm{a}, \mathrm{c}), 2 \mu \mathrm{m}(\mathrm{b})$.

\section{Mature oocytes}

They are semi- squared or semi- circled structures located centrally in the ovarian follicles (Figs.6a-c). Each of them contains small eccentric nucleus with welldeveloped nucleolus (Figs. 6a-b, d), they may be deformed when become in contact with other adjacent cells (Fig. 6e, f). At this stage, the cytoplasm has clusters of vitelline materials adjacent to the Golgi complex mitochondria, lipids droplets and cortical granules (Figs. 6a-d).

The most obvious character in mature oocytes is presence of three types of inclusion bodies in their ooplasm and small spherical or oval electron dense cortical granules which are numerous within the cortical ooplasm (Figs. 6a, e, f). Few oval lipid droplets could be detected in some cells. Vitelline materials are aggregated as shell globules cluster adjacent the Golgi complex in the interstitial syncytium space near the early stage of mature oocyte (Figs. 6b, c).

The plasma membrane surface is detached to form lamellar bodies. The presence of these bodies is rarely noticed through the cytoplasm of some of these cells (Figs. 6b, d-e). In some maturing oocytes the surface of the plasma membrane becomes elevated to form piles of lamellae. These lamellae are thin, long, branched and be made up of a two layers. In some regions of the oocyte; lamellae lie close and parallel to the surface (Fig. 6f), while in others they are separate and intermixed with similar lamellae of adjacent oocytes (Fig. 6g). 


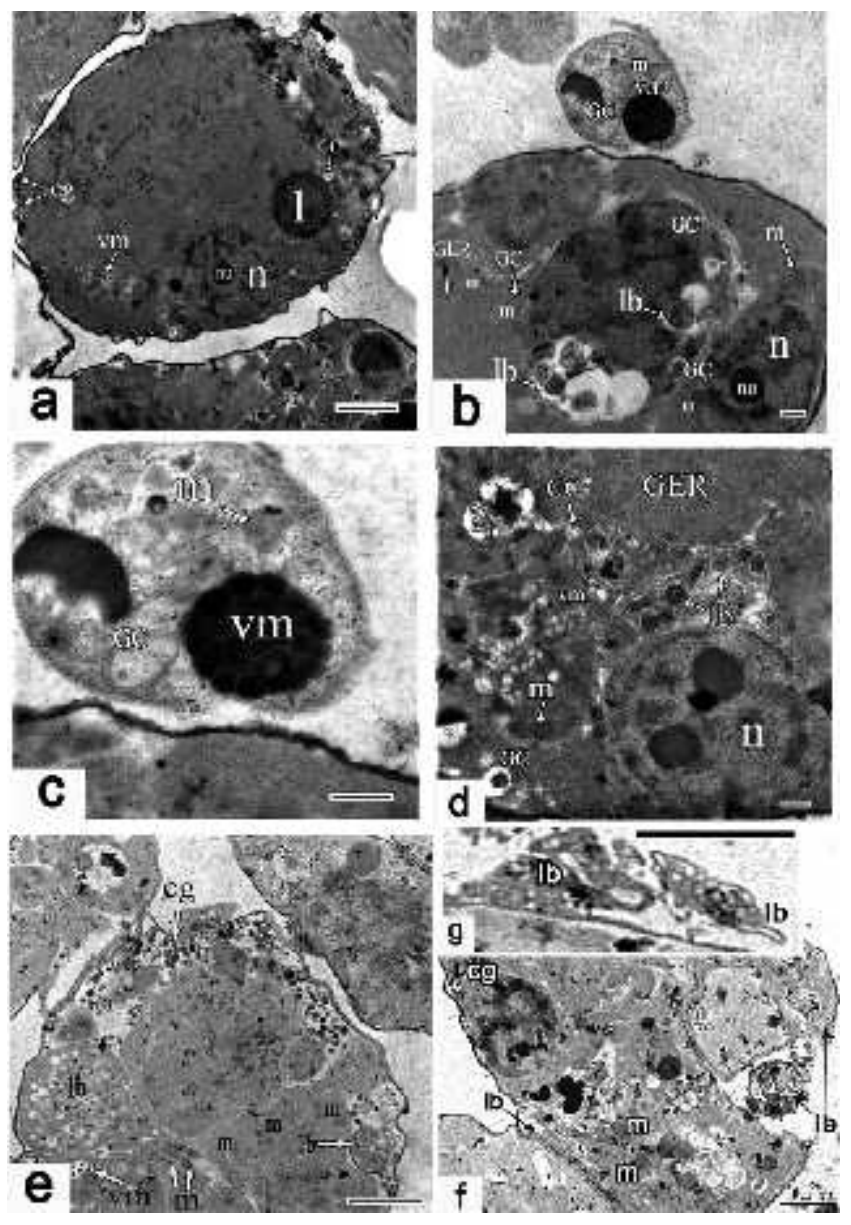

Fig. 6: Transmission electron micrographs of mature oocytes (a-g) of Polyonchobothrium clarias showing.

a. eccentric nucleus(n), well-developed nucleolus (nu), vitelline materials (vm), Golgi complex (GC), lipid droplet (l), cortical granules (cg).

b. lamellar bodies $(\mathrm{lm})$, eccentric nucleus(n), well-developed nucleolus (nu), vitelline materials in clusters (vm), Golgi complex (GC), numerous mitochondria (m), granular endoplasmic reticulum (GER).

c. enlarged part of b show vitelline materials in clusters (vm) adjacent to Golgi complex (GC), mitochondria $(\mathrm{m})$.

d. eccentric nucleus (n), well-developed nucleolus (nu), vitelline materials in clusters (vm) adjacent to Golgi complex (GC), lamellar bodies (lm).

e. deformed oocyte has lamellar bodies $(\mathrm{lm})$, cortical granules $(\mathrm{cg})$, mitochondria $(\mathrm{m})$, vitelline materials (vm)

f. deformed oocyte has lamellar bodies (lm), cortical granules (cg), mitochondria (m).

g. enlarged separated lamellar bodies $(1 \mathrm{~m})$.

Scale bar: $2 \mu \mathrm{m}$ (a, e-g), $500 \mu \mathrm{m}$ (b-d).

\section{DISCUSSION}

The different developmental stages of flatworms' oogenesis starting from oogonial cells, primary and secondary oocytes until reaching the mature oocytes. This is achieved by series of several divisions which distinguish with high activity of these cells (Grant et al., 1977; Holy and Wittrock, 1986; Tappenden et al., 1993; Poddubnaya, 2002; Poddubnaya et al., 2005a and b).

In the present study the oogonia were undergoing a similar differentiation where the general pattern of oogenesis in adult P. clarias (Bothriocephalidae) is similar to 
other species in lower cestodes as in spathebothriideans (Poddubnaya et al., 2005a), caryophyllideans (Poddubnaya et al., 2003) and davaineidians (Taeleb and Ghobashy, 2014).

The present ultrastructural differences of developing cells of $P$. clarias during the oogenesis are more obvious than that reported for Killigrewia delafondi (Taeleb and Abdel-Moaty, 2011) and Cotugnia polycantha (Taeleb and Ghobashy, 2014). In the present study the vitelline materials first appeared in primary oocyte stage, however, they appear in secondary oocytes in Cotugnia polycantha (Taeleb and Ghobashy, 2014) and in mature oocyte in Killigrewia delafondi (Taeleb and AbdelMoaty, 2011). The vitelline materials appear in early stage of primary oocytes then increase at late stage of secondary oocytes and the mature oocytes. The aggregation of vitelline materials as shell globules cluster coated by part of cytoplasm and is existed in the interstitial syncytium space near the early stage of mature oocyte could be correlated to the importance of the vitelline material as a source of energy for maturing the oocytes. Conn (1988) reported that vitellocyte vesicles in cyclophyllidean cestodes, whose oocytes lack cortical granules, play a role in fertilization procedures similar to the cortical granules of other animal phyla. Whereas the cortical granules of numerous animal taxa are connected with fertilization process particularly production of a fertilization membrane (Conn, 2000). And several Cestode species have not cortical granules in the oocytes cytoplasm (Swiderski, 1976; Mokhtar-Maamouri, 1980; Swiderski and Conn, 1999 and Swiderski et al., 2004).

In the current study lipid droplets are rarely detected except in the secondary and few mature-oocytes. As the biosynthesis of lipid depends on the host's fatty acids (Buteau et al., 1971and Nakagawa et al., 1987) and the fatty acid composition of parasite is just similar to that in their direct environment within the host and the host's fatty acids are derived from its food chain (Beach et al., 1975), it could be concluded that the quantity of lipids in a parasite's tissue is generally host-related, and the presence of lipid droplets in the oocytes considered as an energy reserve.

In the present work the numerous cortical granules particularly in the mature oocytes of $P$. clarias were observed in the developing oocytes (secondary and mature) near the plasma membrane. The fine structure of these granules are closely resembles that of another spathebothriidean species; Cyathocephalus truncates, Diplocotyle olrikii and Didymobothrium rudolphii. (Poddubnaya et al., 2005a, b and 2007) and Cotugnia polycantha (Taeleb \& Ghobashy, 2014). On the other hand, Spence and Silk (1971), Erasmus (1973) and Awad and Probert (1990) described the presence of a dense core with a number of outer "lamellae" in cortical granules of some trematodes. This variation in morphology of cortical granules in different worms may indicate variations in chemical composition and little informations about the chemical composition of these granules. According to Guraya (1982), cortical granules in both invertebrate and vertebrate species are composed of protein and carbohydrates. Anderson (1968) and Boyer (1972) have indicated the presence of proteins and acid or neutral polysaccharides in cortical granules of echinoid and polyclad turbellarians. Anderson (1968), Halton et al. (1976) and Spot-Ehlers (1991) reported that the structure of cortical granules is useful in phylogenetic studies of Platyhelminthes.

The present observations revealed the syncytial interstitial tissue is existent as epithelial sheath of the ovarian follicles and projection into the lumen of each ovarian follicle. This tissue contains mitochondria, lipid droplets and free ribosomes. Such interstitial cells are supposed to be responsible for the transport of nutrients and energy sources for intercellular exchange (Gresson, 1964; Orido, 1987; Conn, 1993; Swiderski and Xylander, 2000; Poddubnaya, 2003a; Poddubnaya et al., 2005a; 
Poddubnaya et al., 2007 and Conn et al., 2009). This tissue contain mitochondria, lipid droplets, free ribosomes and myelin like bodies, also these tissue processes may be have vitelline material and large accumulation of light or moderately electron dense homogeneous materials (Taeleb and Ghobashy, 2014).

The present study revealed a number of myelin like bodies appearing through the cytoplasm of ovarian interstitial tissues in different irregular shapes, this is resemble to that reported in Killigrewia delafondi, and Didymobothrium Rudolphii (Taeleb and Abdel-Moaty, 2011 and Poddubnaya et al., 2007) and in Cotugnia polycantha (Taeleb \& Ghobashy, 2014). Where Poddubnaya et al. (2007) noticed these structures in mature oocytes and concluded that the importance of these structures as source of energy and they are considered as heterogeneous lysosomal variation.

In the present study the surface covering of maturing oocytes of $P$. clarias is prolonged into lamellae resembling that of Diplocotyle olrikii (Poddubnaya et al., 2005b), while the surfaces of the maturing oocytes of Cyathocephalus truncates and Didymobothrium rudolphii. (Poddubnaya et al., 2005a and 2007) do not have a pronounced lamellar surface. Our opinion is agreed with Poddubnaya et al. (2005b) suggestion that this prolongation increasing the oocyte transport surface for receiving nutrients from the interstitial syncytial cytoplasm.

\section{CONCLUSION}

Adult $P$. clarias Woodland, 1925 was recovered from the intestine of the fish Clarias gariepinus, Burchell, 1822, from different localities; fresh water system in Egypt; in Al-Qaliobiah province and in some fish farms in Sharqiyah province. The fine structure of the ovary and oogenesis process is described. The oocytes undergo characteristic cytological changes that lead to oocyte maturation. Vitelline material appears in early stages of primary oocytes. Lipid droplets appeared in late stages of secondary oocyte. Mature oocytes are filled with clusters of cortical granules adjacent to the oocyte plasma membrane. Syncytial interstitial tissue and a number of myelinlike bodies are observed in the ovarian cytoplasm and they fill the cytoplasmic spaces.

\section{REFERENCES}

Abdel-Gaber, R.; Abdel-Ghaffar, F.; Bashtar, A.R. and Morsy, K. (2016). Interactions between the intestinal cestode Polyonchobothrium clarias (Pseudophyllidea: Ptychobothriidae) from the African sharptooth catfish Clarias gariepinus and heavy metal pollutants in an aquatic environment in Egypt. J. Aquat. Biol. \& Fish., 90(6): $742-752$.

Adiyodi, K.G. and Adiyodi, R.G. (1988). Accessory sex gland in: K.G. Adiyodi and R.G. Adiyodi (Eds.). Reproductive biology of invertebrates. John Willey and Sons, New York., pp. 1-50.

Anderson, E. (1968). Oocyte differentiation in the sea urchin Arbaciap unctulata with particular reference to the origin of the cortical granules and their participation in the cortical reactions. Journal of Cell Biology., 37: 514-539.

Awad, A.H.H. and Probert, A.J. (1990). Scanning and transmission electron microscopy of the female reproductive system of Schistosoma margrebowiei Le Roux, 1933. Journal of Helminthology, 64: 181-192.

Beach, D.H.; Sherman, I.W. and Holtz, D.H. (1975). Incorporation of docosahexaenoic fatty acid into the lipids of a cestode of marine elasmobranchs. J. Parasitol., 59: 655-666. 
Bjorkman, N. and Thorsell, W. (1964). On the ultrastructure of the ovary of the liver fluke (Fasciola hepatica L.). Zeitschrift für Zellforschung und Mikroskopische Anatomie., 63(4): 538-549.

Boyer, B.A. (1972). Ultrastructural studies of differentiation in the oocyte of the polyclad turbellarian, Prostheceraeus floridianus. Journal of Morphology, 136, 273-296.

Buteau, G.H.; Simmons, J.E.; Beach, D.H.; Holtz, D.H. and Sherman, I.W. (1971). The lipids of cestodes from Pacific and Atlantic coast triakid sharks. J. Parasitol., 57: 1272-1278.

Cheng, T.C. (1986). General Parasitology (2nd edn). Academic Press, Division of Hardcourt Brace \& Company, USA., pp. 402-416.

Conn, D.B. (1988). Are vitelline cell globules a mechanism for polyspermy prevention in cyclophyllidean cestodes? Transac-tions of the American Microscopical Society,107, 106.

Conn, D.B. (1993). Ultrastructure of the gravid uterus of Hymenolepis diminuta (Platyhelminthes: Cestoda). J. Parasitol., 79:583-590.

Conn, D.B. (2000). Atlas of invertebrate reproduction and development. Wiley-Liss, Inc., New York.

Conn, D.B.; Młocicki, D. and Swiderski, Z. (2009). Ultrastructure of the early gravid uterus of Corallobothrium fimbriatum (Cestoda: Proteocephalidea). Parasitol. Res., 105: 989996.

Davydov, V.G.; Poddubnaya, L.G. and Kolesnicova, G.A. (1994). Ultrastructure of genital system ducts of Caryophyllaeus laticeps (Cestoda, Caryophyllidea). Parazitologiya, 28: 501-509.

Douglas, L.T. (1963).The development of organ systems in nematotaeniid cestodes. 111.Gametogenesis and embryonic development in Baerietta Diana and Distoichometra kosloffi. J. Parasitol., 49:530- 558.

Erasmus, D.A. (1973): A comparative study of the reproductive system of mature, immature and "unisexual" female Schistosoma mansoni. Parasitology, 67:165-83.

Grant, W.C.; Hair Kema, R. and Muse K.E. (1977). Ultrastructure of Pharyngostomoides procyonis Harkema, 1942 (Diplostomatidae). II. The female reproductive system. J. Parasitol., 63:1019-1030.

Gresson, R.A.R. (1964). Oogenesis in the hermaphroditic Digenea (Trematoda). Parasitology, 54: 409-421.

Guraya, S.S. (1982). Recent progress in the structure, origin, composition and function of the cortical granules in animal eggs. International Review of Cytology, 78: 257-360.

Halton, D.W.; Stranock, S.D. and Hardcastle, A. (1976). Fine structural observations on oocyte development in monogeneans. Parasitology, 73: 13-23.

Holy, J.M. and Wittrock, D.D. (1986) Ultrastructure of the female reproductive organs (ovary, vitellaria, and Mehlis' gland) of Halipegus eccentricus (Trematoda: Derogenidae). Can. J. Zool., 64: 2203-2212.

Ibrahim, A.; Taha, H. and El-Naggar, M. (2008). Redescription of the cestode Polyonchobothrium Clarias and its histopathological impact on the stomach of Clarias gariepinus. Egypt. J. Aquat. Biol. \& Fish,12(4): 165-174.

Korneva, J.V. (2001a). Ultrastructure of the female genital system in Proteocephalus torulosus and P. exiguus (Cestoda: Proteocephalidea). Helminthologia, 38: 67-74.

Korneva, Z.h.V. (2002). Ultrastructural organization of reproductive system in Triaenophorus nodulosus (Cestoda, Pseudophyllidea). Zoologicheskiy Zhurnal., 81: 1432-1438.

Korneva, Z.h.V. and Davydov, V.G. (2001). The female reproductive system in the proteocephalidean cestode Gangesia parasiluri (Cestoda,Proteocephalidea). Zoologicheskiy Zhurnal., 80:131-144 (In Russian).

Korneva, Z.h.V. and Davydov, V.G. (2001). The female reproductive system in the proteocephalidean cestode Gangesia parasiluri (Cestoda,Proteocephalidea). Zoologicheskiy Zhurnal., 80:131-144 (In Russian).

McDougald, L.R. (2003). Cestodes and trematodes. In: Diseases of Poultry, 11th edn (YM Saif, HJ Barnes, AM Fadly, JR Glisson, LR McDougald \& DE Swayne, eds). Iowa State Press, USA., pp. 396- 404. 
Mokhtar-Maamouri, F. (1980). Particularités des processus de la fecundation chez Acanthobothrium filicolle Zschokke, 1888 (Cestoda: Tetraphyllidea, Onchobothriidae). Archives de l'Institute Pasteur Tunis., 57: 191-205.

Nakagawa, A.; Fukushima, T. and Fukumoto, S. (1987). Fatty acid composition of diphyllobothriid cestodes with reference to their hosts. Yonago Acta Medica., 30: 6580.

Orido, Y. (1987). Development of the ovary and female reproductive cells of the lung fluke, Paragonimus ohirai (Trematoda: Troglotrematidae). J. Parasitol. 73: 161-171.

Orido, Y. (1988). Fertilization and oogenesis of the lung fluke, Paragonimus ohirai (Trematoda: Troglotrematidae). International Journal for Parasitology, 18: 973-980.

Poddubnaya, L.G. (2002). Ultrastructure of genital system ducts of Diphyllobothrium latum (Cestoda: Pseudophyllidea): The ducts of the female reproductive system. Parazitologiya, 36: 79-87.

Poddubnaya, L.G. (2003a). Structure of reproductive system of the amphicotylide cestode Eubothrium rugosum (Cestoda, Pseudophyllidea). Journal of Evolutionary Biochemistry and Physiology, 39: 345-355.

Poddubnaya, L.G. (2003b). Ultrastructure of reproductive organs and ducts in the progenetic species Archigetes sieboldi (Cestoda, Caryophyllidea). Zoologicheskiy Zhurnal, 82: $1038-1050$.

Poddubnaya, L.G.; Gibson, D.I. and Olsen, P.D. (2007). Ultrastructure of the ovary ,ovicapt ,and oviduct of the spathebothriidean tapworm Didymobothrium rudolphii (Monticelli),1890). Acta Parasitol., 52: 127-134.

Poddubnaya, L.G.; Kuchta, R.; Scholz, T. and Xylander, W.E.R. (2010). Ultrastructure of the ovarian follicles, oviducts and oocytes of Gyrocotyle urna (Neodermata: Gyrocotylidea). Folia Parasitologia, 57(3): 173-184.

Poddubnaya, L.G.; Mackiewicz, J.S. and Kuperman, B.I. (2003). Ultrastructure of Archigetes sieboldi (Cestoda: Caryophyllidea): relationship between progenesis, development and evolution. Folia Parasitologica, 50: 275-293.

Poddubnaya, L.G.; Mackiewicz, J.S.; Brunanska, M. and Scholz, T. (2005b). Ultrastructural studies on the reproductive system of progenetic Diplocotyle olrikii (Cestoda: Spathebothriidea): ovarian tissue. Acta Parasitol., 50: 199-207.

Poddubnaya, L.G.; Mackiewicz, J.S.; Brunanska, M. and Scholz, T. (2005a). Fine structure of the female reproductive ducts of Cyathocephalus truncatus (Cestoda: Spathebothriidea), from salmonid fish. Folia Parasitologica, 52: 323-338.

Podvyaznaya, I.M. (2003). Ultrastructural studies of the female reproductive system in a parasite of bats Allassogonoporus amphoraeformis (Digenea: Allassogonoporidae). Parazitologiya, 37: 387-393.

Rybicka, K. (1966). Embryogenesis in cestodes. Adv. Parasitol., 4: 107- 186.

Sopott-Ehlers, B. (1991). Electron microscopical observations on vitellocytes and germocytes in Nematoplana coelogynoporoides (Platyhelminthes; Proseriata). Zoomorphology, 110: 293- 300.

Spence, I.M. and Silk, M.H. (1971). Ultrastructural studies of the blood fluke Schistosoma mansoni. V. The female reproductive system-A preliminary report. South African Journal of Medical Science, 36: 41-50.

Swiderski, Z. (1976). Fertilization in the cestode Hymenolepis diminuta (Cyclophyllidea, Hymenolepididae). Proceedings of the 6th European Congress of Electron Microscopy, 14-20 September, 2: 311.312.

Swiderski, Z. and Conn, D.B. (1999). Ultrastructural aspects of fertilization in Proteocephalus longicollis, Intermicapsifer madagasca- riensis, and Mesocestoides lineatus (Platyhelminthes, Cestoda). Acta Parasitologica, 44: 19-30.

Swiderski, Z. and Xylander, W.E.R. (2000). Vitellocytes and vitellogenesis in cestodes in relation to embryonic development, egg production and life cycle. Int. J. Parasitol, 30: 805-817. 
Swiderski, Z.; Conn, D.B.; Miquel, J. and Mocicki, D. (2004). Fertilization in the cestode Gallegoides arfaai (Mobedi et Ghadirian, 1977) Tenora et Mas-Coma, 1978 (Cyclophyllidea, Anoplocephalidae). Acta Parasitologica, 49(2), 108-115.

Taeleb, A.A. and Abdel-Moaty, S.M. (2011). Ultrastructural study of the ovary and oogenesis of the cyclophyllidean tapworm Killigrewia delafondi (Railliet,1892) Meggitt, 1927 from Egypt. Egypt. J. Zool., 56: 93- 108.

Taeleb, A.A. and Ghobashy, M.A. (2014). Fine structural observations on oocyte development, oogenesis and fertilization process of Cotugnia polycantha Diamar, 1893 (Cestoda: Davaineidae) infecting doves (Streptopelia senegalensis). African Journal of Biotechnology, 13: 3204-3216.

Tappenden, T.; Kearn, G.C. and Evans-Gowing, R. (1993). Fertilization and the functional anatomy of the germarium in the monogenean Entobdella soleae. International Journal for Parasitology, 23: 901-911.

Ubelaker, J.E. (1983). The morphology, development and evolution of tapeworm larvae. In: C. Arme and P.W. Pappas (Eds.), Biology of the Eucestoda. Vol. 1. Academic Press, London, pp. 235-296.

\section{ARABIC SUMMARY}

\section{Polyonchobothrium دراسة التركيب الدقيق للمبيض و مراحل تكوين البويضات في الدودة الثريطية Clarias التي تصيبclarias Woodland, 1925 (Cestoda: Bothriocephalidea) gariepinus}

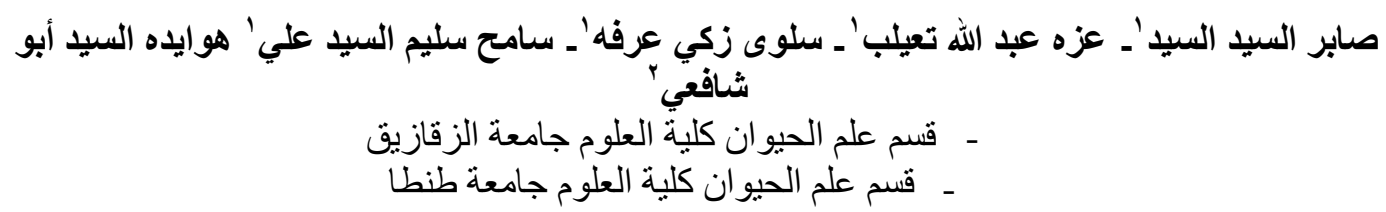

clarias Woodland, 1925 تم وصف التركيب الدقيق لأنسجة المبيض و مر احل تكوين البويضات Clarias gariepinus البالغين المستخرجة من الأمعاء الدقيقة من أسماك

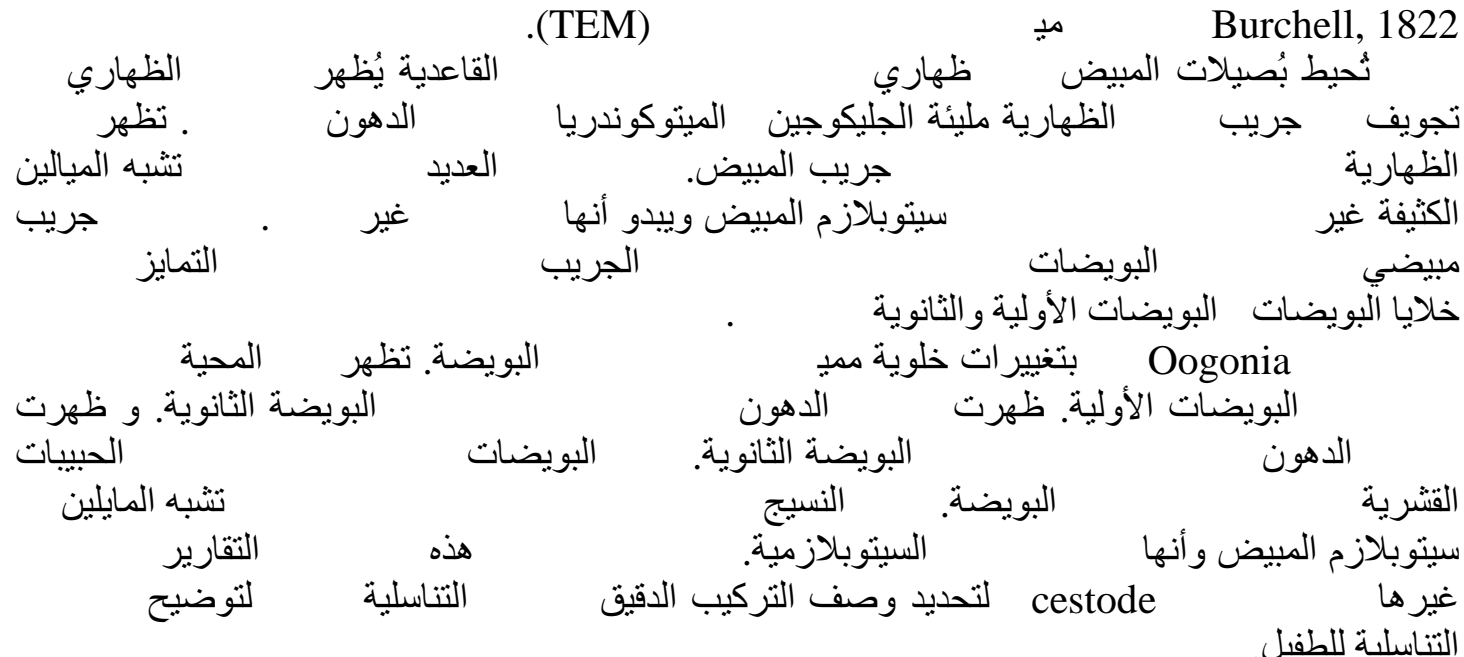

